\title{
Estudo da significância de variáveis de compactação e sinterização de pastilhas de $\beta$-TCP utilizando planejamento de experimentos
}

\section{(Study of the significance of pressing and sintering variables on $\beta-T C P$ tablets using experimental design)}

\author{
R. N. Oliveira, F. S.Alencastro, G.D.A. Soares \\ Programa de Engenharia Metalúrgica e de Materiais, COPPE, UFRJ, C. P. 68505, Rio de Janeiro, RJ 21941-972 \\ renataoliveira@poli.ufrj.br
}

\begin{abstract}
Resumo
Dentre as cerâmicas de uso biomédico destaca-se o fosfato tricálcico do tipo $\beta$ ( $\beta$-TCP). Pós cerâmicos são normalmente compactados e sinterizados em altas temperaturas para sua densificação e consequente aumento da resistência mecânica. Uma forma de otimizar a densificação de corpos cerâmicos é analisar a significância das variáveis de processamento por meio de um planejamento de experimentos. $\mathrm{O}$ objetivo deste trabalho foi determinar a significância dos seguintes parâmetros: pressão de compactação uniaxial (28 e $111 \mathrm{MPa}$ ); calcinação prévia do pó (como recebido - não calcinado e calcinado a $650{ }^{\circ} \mathrm{C}$ ); temperatura e tempo de sinterização (respectivamente, 900 e $1150{ }^{\circ} \mathrm{C}, 2 \mathrm{e} 4 \mathrm{~h}$ ). As pastilhas produzidas foram caracterizadas por microscopia eletrônica de varredura, difração de raios X e espectroscopia no infravermelho, enquanto que a microdureza e a retração linear foram consideradas as respostas do planejamento. Observou-se que o aumento da pressão de compactação e da temperatura de sinterização foram os parâmetros mais importantes para a densificação das amostras. As pastilhas sinterizadas a $1150{ }^{\circ} \mathrm{C}$ apresentaram tamanho médio de grão entre 1 e $2 \mu \mathrm{m}$ e retração linear máxima de aproximadamente $20 \%$, bem superior à das amostras sinterizadas a $900{ }^{\circ} \mathrm{C}$, que não apresentaram completa densificação. Não foram identificadas outras fases que não o $\beta$-TCP e também não foram observadas microtrincas nas amostras sinterizadas.
\end{abstract}

Palavras-chave: fosfato tricálcico, planejamento de experimentos, sinterização, densificação.

Abstract

Among the ceramic materials for biomedical applications, tricalcium phosphate type $\beta$ ( $\beta$-TCP) can be highlighted. Usually, ceramic powders are pressed and densified at high temperatures in order to improve the mechanical strength. One way to optimize the densification of ceramic bodies is to analyze the significance of processing variables using an experimental design. The purpose of this work is to determine the significance of the following parameters: uniaxial pressure (28 and $111 \mathrm{MPa})$; previous thermal treatment of the powder (as-received-non-calcined and calcined at $\left.650{ }^{\circ} \mathrm{C}\right)$; sintering temperature and time $\left(900\right.$ and $1150{ }^{\circ} \mathrm{C}, 2$ and $4 \mathrm{~h}$, respectively). The produced tablets were characterized by scanning electron microscopy, X-ray diffraction and infrared spectroscopy, while linear shrinkage and microhardness results were considered as responses of the experimental design. It was observed that the uniaxial pressure and sintering temperature were the most important parameters for samples densification. The average grain size of the tablets sintered at $1150{ }^{\circ} \mathrm{C}$ was approximately 1-2 $\mu$ m and maximum linear shrinkage of, approximately, $20 \%$, well above the values found for the samples sintered at $900{ }^{\circ} \mathrm{C}$, which did not present complete densification. Phases other than $\beta$-TCP were not present in the sintered samples and no cracking was observed.

Keywords: tricalcium phosphate, experimental design, sintering, densification.

\section{INTRODUÇÃO}

Dentre as biocerâmicas que mimetizam o osso humano, destacam-se os fosfatos de cálcio por sua similaridade química com esse tecido, o qual é composto basicamente de colágeno tipo I e de hidroxiapatita cálcio deficiente com substituições iônicas [1-4]. No entanto, a hidroxiapatita $\left(\left[\mathrm{Ca}_{10}\left(\mathrm{PO}_{4}\right)_{6}(\mathrm{OH})_{2}\right], \mathrm{HA}\right)$ sintética apresenta baixa taxa de reabsorção $[2,5] \mathrm{e}$, muitas vezes é empregada misturada ao fosfato tricálcico.

Fosfato tricálcico tipo $\beta\left[\mathrm{Ca}_{3}\left(\mathrm{PO}_{4}\right)_{2}, \beta-\mathrm{TCP}\right]$, obtido a partir da sinterização de hidroxiapatita cálcio-deficiente, é uma fase reabsorvível, o que permite sua substituição gradual pelo tecido neoformado. A temperatura de sinterização deve ser ajustada para evitar a transformação $\beta$-TCP $\rightarrow \alpha$-TCP, pois essas fases apresentam densidades diferentes $\left(3,07 \mathrm{~g} / \mathrm{cm}^{3}\right.$ e $2,86 \mathrm{~g} / \mathrm{cm}^{3}$, respectivamente)e, no resfriamento, a contração diferencial gera microtrincas que fragilizam o material [5,6]. Alguns autores defendem que a sinterização do $\beta$-TCP deva ser realizada em temperaturas de até $1120{ }^{\circ} \mathrm{C}$ (temperatura de transformação $\beta$-TCP $\rightarrow \alpha$-TCPé igual a $1125^{\circ} \mathrm{C}$ ) [5], enquanto outros autores obtiveram resistência mecânica mais elevada para corpos densificados a $1200^{\circ} \mathrm{C}$ com ausência de trincas. [6] Tal variação pode ser justificada com base na razão $\mathrm{Ca} / \mathrm{P}$ das amostras, 
uma vez que, de acordo com o diagrama de equilíbrio, pequenas alterações dessa modificam substancialmente a temperatura de transformação $\beta \rightarrow \alpha$ [7]. A sinterização da hidroxiapatita foi dividida em dois estágios [8]: no primeiro ocorre a aproximação das partículas e formação de pescoço entre elas, acompanhado da redução da área superficial, enquanto que, no segundo estágio, há considerável redução de porosidade e consequente densificação do corpo. Ao estudar cerâmicas à base de fosfato de cálcio, alguns autores caracterizam a resistência mecânica dos corpos com base nos resultados de dureza [7,9].

Além dos fatores tempo e temperatura de sinterização, a densificação depende das velocidades de aquecimento e resfriamento; da distribuição granulométrica do pó, e das condições de compactação [10, 11]. A sinterização de hidroxiapatita em forno convencional pode gerar tensões térmicas no corpo devido à baixa condutividade de calor e alta contração da hidroxiapatita [12]. Portanto, a taxa de aquecimento não deveria exceder $5^{\circ} \mathrm{C} / \mathrm{min}$ [12]. Em relação à densificação de amostras de $\beta$-TCP, diferentes grupos utilizam $5{ }^{\circ} \mathrm{C} / \mathrm{min}$ ou $10^{\circ} \mathrm{C} / \mathrm{min}$, sem prejuízo à sinterização $[7,13,14]$.

A área superficial das partículas pode ser considerada a força motriz para a densificação. Tratamentos de calcinação do pó precursor poderiam otimizar o processo de sinterização. Não há consenso, entretanto, sobre o efeito positivo da calcinação previa do pó na densificação da cerâmica. O pó de hidroxiapatita é calcinado a $650{ }^{\circ} \mathrm{C}$ para redução de área superficial, o que facilitaria o processo de aproximação, otimizando a densificação [15]. As condições de compactação (pressão e tempo empregados) também afetam a densificação de corpos cerâmicos. A compactação deve ser uniforme, pois variações de densidade no corpo verde podem levar à contração diferencial na queima com subsequente trincamento da amostra [16].

O planejamento de experimentos é uma ferramenta adequada para se identificar as variáveis mais influentes em um dado processo [17]. Assim, o presente trabalho tem o intuito de determinar a significância de algumas variáveis de processo na densificação de pós de $\beta$-TCP.

\section{MATERIAIS E MÉTODOS}

A matéria prima para produção das pastilhas foi apatita cálcio-deficiente (fosfato tricálcico, Merck). O pó (previamente calcinado ou não) foi compactado uniaxialmente em prensa Carver (4350L, EUA), seguida de sinterização em forno mufla com atmosfera não controlada (Jung 0613, Brasil). Foi realizado um planejamento de experimentos no programa Minitab $15^{\circledR}$, com quatro variáveis em dois níveis. As variáveis utilizadas com os respectivos níveis estão listadas a seguir: pressão uniaxial aplicada na compactação das pastilhas: $28 \mathrm{MPa}$ e $111 \mathrm{MPa}$; pó como recebido (não calcinado) ou pó previamente calcinado a $650^{\circ} \mathrm{C}$ por $30 \mathrm{~min}$; temperatura de sinterização: $900{ }^{\circ} \mathrm{C}$ e $1150{ }^{\circ} \mathrm{C}$ e tempo de sinterização: $2 \mathrm{~h}$ e $4 \mathrm{~h}$. O planejamento gerou 16 condições, mostradas na Tabela I, correspondendo à combinação de todas as diferentes variáveis. Foram produzidas dez pastilhas de cada condição. Outros parâmetros, como a massa das pastilhas e a rampa de aquecimento, foram mantidos constantes e iguais a $0,3 \mathrm{~g}$ e $10^{\circ} \mathrm{C} / \mathrm{min}$, respectivamente.

Tabela I - Variáveis de processo empregadas na produção das pastilhas.

[Table I - Processing variables used in tablets production.]

\begin{tabular}{ccccc}
\hline & \multicolumn{2}{c}{ Compactação das } & \multicolumn{2}{c}{ Sinterização } \\
pastilhas & $\begin{array}{c}\text { Pressão } \\
\text { uniaxial } \\
\text { Id. }\end{array}$ & $\begin{array}{c}\text { Calcinação } \\
\text { do pó }\end{array}$ & $\begin{array}{c}\text { Temperatura } \\
\left({ }^{\circ} \mathrm{C}\right)\end{array}$ & $\begin{array}{c}\text { Tempo } \\
\text { (h) }\end{array}$ \\
\hline 1A & 28 & Não & 900 & 2 \\
1B & 28 & Não & 900 & 4 \\
1C & 28 & Não & 1150 & 2 \\
1D & 28 & Não & 1150 & 4 \\
2A & 111 & Não & 900 & 2 \\
2B & 111 & Não & 900 & 4 \\
2C & 111 & Não & 1150 & 2 \\
2D & 111 & Não & 1150 & 4 \\
3A & 28 & Sim & 900 & 2 \\
3B & 28 & Sim & 900 & 4 \\
3C & 28 & Sim & 1150 & 2 \\
3D & 28 & Sim & 1150 & 4 \\
4A & 111 & Sim & 900 & 2 \\
4B & 111 & Sim & 900 & 4 \\
4C & 111 & Sim & 1150 & 2 \\
4D & 111 & Sim & 1150 & 4 \\
\hline
\end{tabular}

As respostas do planejamento de experimentos foram microdureza Vickers e retração linear. A medição de microdureza foi com um microdurômetro Vickers (Ernst Leitz Wetzlar, Alemanha). Nas pastilhas sinterizadas a $1150{ }^{\circ} \mathrm{C}$ foi utilizada uma carga de $1 \mathrm{kgf}$ durante $30 \mathrm{~s}$, enquanto que nas pastilhas densificadas a $900{ }^{\circ} \mathrm{C}$ a maior carga possível de ser aplicada sem causar sua fratura foi $0,1 \mathrm{kgf}$, também por $30 \mathrm{~s}$. As pastilhas de cada condição estudada foram analisadas em duplicata, sendo feitas 7 indentações em cada amostra, com espaço de $1 \mu \mathrm{m}$ entre marcas, buscando evitar a propagação de trincas.

A retração linear (RL) de dez amostras de cada condição foi calculada, segundo a equação $\mathrm{A}$, na qual $\mathrm{L}_{1}$ é a espessura original de cada pastilha e $\mathrm{L}_{2}$ a espessura após a sinterização: [13]

$$
\operatorname{RL}(\%)=\left[\left(\mathrm{L}_{1}-\mathrm{L}_{2}\right) / \mathrm{L}_{1}\right]
$$

A morfologia da superfície das pastilhas foi observada por microscopia eletrônica de varredura - MEV (Jeol JSM 6460-LV, Japão), sendo obtidas no mínimo três imagens de regiões aleatórias em cada uma das pastilhas. As imagens das amostras sinterizadas a $1150^{\circ} \mathrm{C}$ foram utilizadas também para 
quantificar a fração volumétrica de poros, com o programa Image Pro-Plus $4.0^{\circledR}$, bem como quantificar o diâmetro médio de grão por meio do procedimento dos interceptos circulares, conforme a norma ASTM E112-10 [18].

As fases no pó como recebido, no pó calcinado a nas pastilhas sinterizadas foram identificadas por difração de raios $\mathrm{X}$ (DRX) e espectroscopia no infravermelho por transformada de Fourier (FTIR). As pastilhas foram maceradas em gral de ágata para essas análises. A análise no difratômetro de raios X (Shimadzu XRD-6000) foi com alvo de cobre, varredura entre $20^{\circ}$ e $40^{\circ}$, passo $0,02^{\circ}$ e varredura $1 \%$ min, enquanto que as análises por FTIR (Perkin Elmer, Spectrum 100) foram feitas na faixa de número de onda entre 1200 e $550 \mathrm{~cm}^{-1}$ com 16 varreduras para cada amostra.

\section{RESULTADOS E DISCUSSÃO}

A Tabela II mostra os resultados de microdureza e retração linear das amostras processadas segundo as condições apresentadas na Tabela I. Observa-se uma maior retração linear nas pastilhas sinterizadas a $1150^{\circ} \mathrm{C}$ quando comparadas com as amostras densificadas a $900{ }^{\circ} \mathrm{C}$ (aproximadamente 17 vezes maior), bem como maior dureza (em média 180 vezes maior). Diferentes autores também observaram maior contração e maior dureza em amostras de fosfato de cálcio sinterizadas em temperatura mais elevada $[7,10,19,20]$. A máxima retração linear das pastilhas densificadas a $1150{ }^{\circ} \mathrm{C}$ foi aproximadamente $20 \%$.

A significância dos parâmetros para microdureza e

Tabela II - Resultados de microdureza e retração linear. [Table II - Results of microhardness and linear shrinkage.]

\begin{tabular}{ccccc}
\hline & \multicolumn{2}{c}{ Microdureza } & \multicolumn{2}{c}{ Retração linear } \\
Id. & Média & D.P. & Média & D.P. \\
& (Hv) & $(\mathrm{Hv})$ & $(\%)$ & $(\%)$ \\
\hline 1A & 0,8 & 0,1 & 2,4 & 3,7 \\
1B & 1,2 & 0,1 & 2,1 & 1,8 \\
1C & 107,4 & 17,1 & 13,1 & 5,3 \\
1D & 114,1 & 18,8 & 21,7 & 2,3 \\
2A & 7,3 & 1,5 & 3,0 & 2,0 \\
2B & 7,2 & 1,7 & 4,6 & 2,0 \\
2C & 222,6 & 66,3 & 13,6 & 3,6 \\
2D & 247,3 & 42,7 & 20,6 & 2,9 \\
3A & 0,7 & 0,1 & $-0,5$ & 2,5 \\
3B & 0,8 & 0,1 & 0,8 & 2,2 \\
3C & 126,0 & 42,3 & 19,4 & 3,4 \\
3D & 138,6 & 33,3 & 22,3 & 3,1 \\
4A & 5,7 & 1,2 & $-2,6$ & 4,3 \\
4B & 7,4 & 1,6 & $-0,9$ & 1,3 \\
4C & 231,9 & 54,5 & 13,6 & 5,4 \\
4D & 232,81 & 62,6 & 20,5 & 2,8 \\
\hline
\end{tabular}

(a) Efeito das variáveis na microdureza

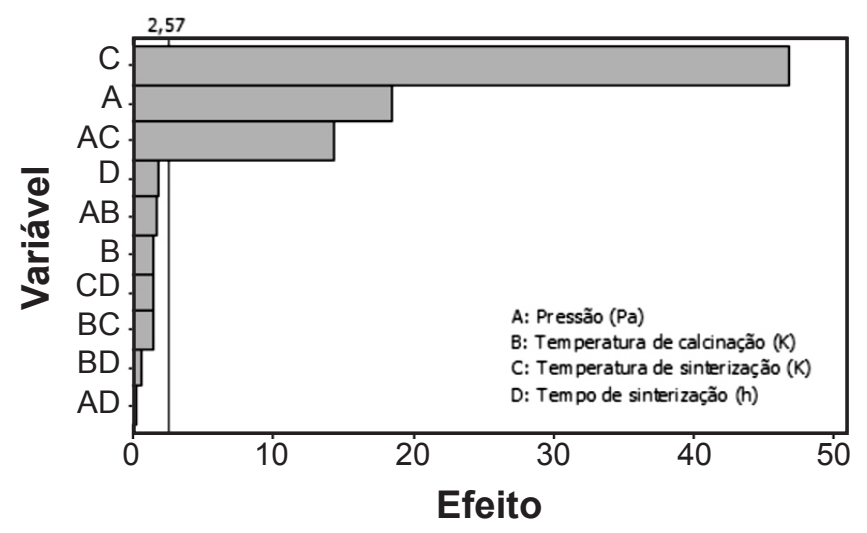

(b) Efeito das variáveis na retração linear

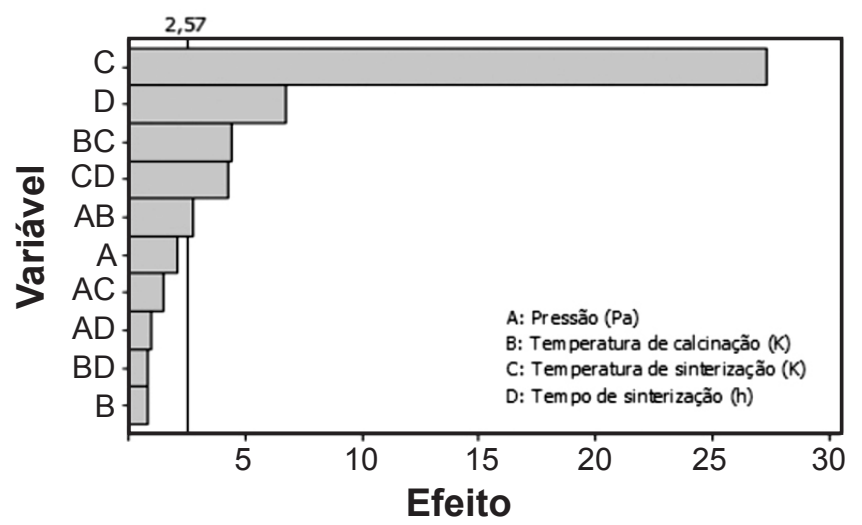

Figura 1: Diagrama Pareto correlacionando as variáveis empregadas com os resultados de (a) microdureza e (b) retração linear.

[Figure 1: Pareto diagram correlating the test variables with the results of (a) microhardness and (b) linear shrinkage.]

retração linear com nível de confiança de $95 \%$ pode ser vista na Fig. 1. Em relação aos resultados de microdureza observa-se que a temperatura de sinterização (parâmetro C) é o de maior influência, seguido da pressão aplicada na manufatura das pastilhas (parâmetro A) e do efeito conjunto desses dois parâmetros (AC). Quanto maior a pressão de compactação, maior a aproximação das partículas, menos espaço vazio há entre elas e menor o tempo para a formação de pescoço, o que resulta em menor porosidade. Com isso, a densificação é maximizada. O aumento da temperatura de sinterização acarreta efeito similar uma vez que maior energia é fornecida ao sistema.

Observa-se que, para a resposta de retração linear, a temperatura de sinterização também foi o parâmetro de maior significância, seguido do tempo (parâmetro D). Além destes, o efeito conjunto da temperatura com a condição do pó (BC), da temperatura com o tempo de sinterização (CD), e da pressão uniaxial aplicada e da condição do pó (AB) também foram considerados significativos, uma vez que o valor de seus efeitos no diagrama Pareto é superior à linha de corte.

A microestrutura das amostras sinterizadas a $900{ }^{\circ} \mathrm{C}$ (Fig. 
2a) mostra o início da aproximação das partículas de pó e a formação de algumas regiões densas. Estas regiões compactas apresentavam faces ortogonais, e foi possível observar a presença de pequenos grãos nas faces destes prismas, o que poderia indicar que nessa temperatura as amostras estavam no início do segundo estágio de sinterização. Segundo as observações do grupo de Viswanath [21], monocristais de $\beta$-TCP crescem segundo a forma da estrutura cristalina do material. Observa-se que nas regiões onde a densificação tem início a estrutura cresce de forma regular, provavelmente segundo a simetria cristalina do material. Nas amostras sinterizadas a $1150{ }^{\circ} \mathrm{C}$ (Fig. 2b) são observados grãos bem definidos e pequenos poros entre os grãos.

Devido à incompleta densificação das pastilhas sinterizadas a $900{ }^{\circ} \mathrm{C}$, não foi possível quantificar a fração volumétrica de poros e o diâmetro médio de grãos. A Tabela
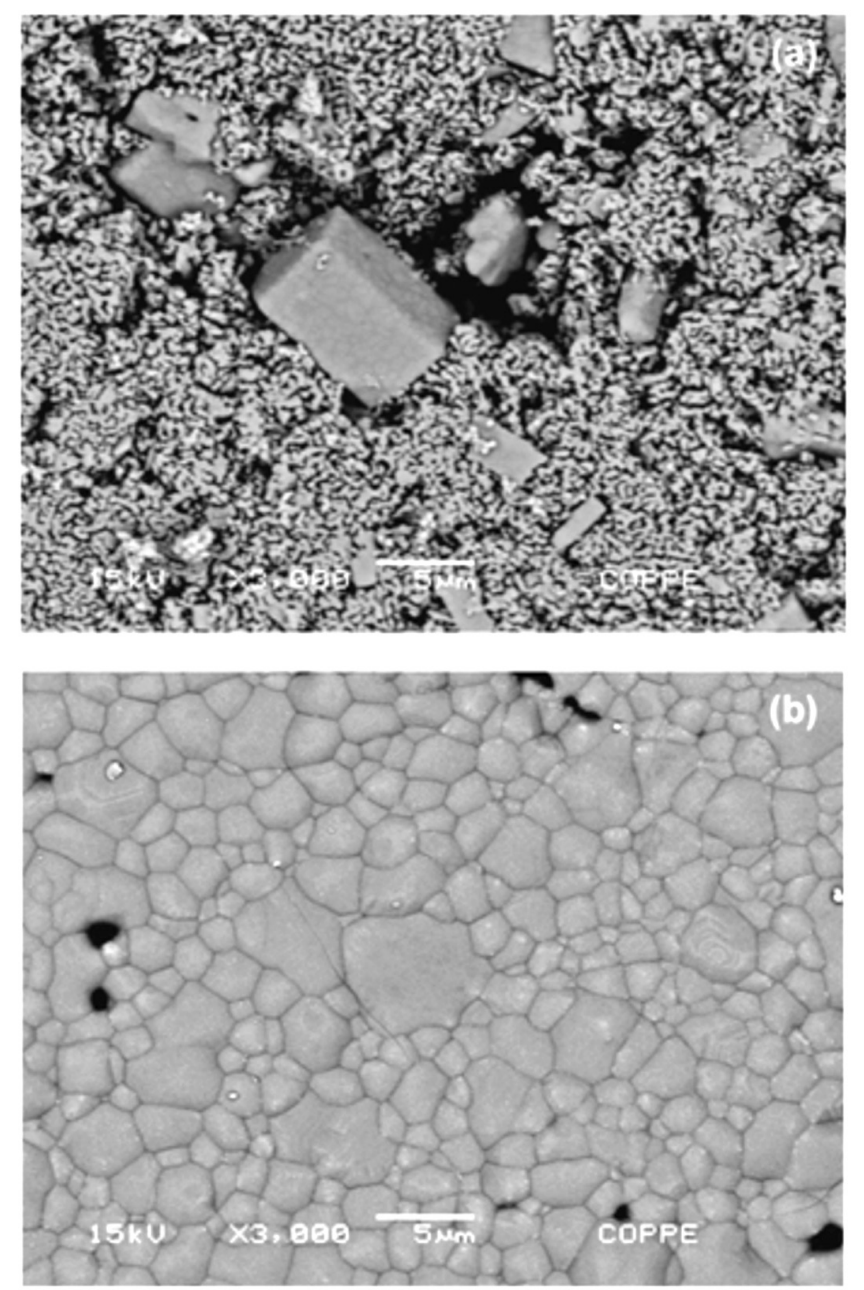

Figura 2: Imagens de MEV de uma amostra sinterizada a (a) $900{ }^{\circ} \mathrm{C}, 1 \mathrm{~A}$ e a (b) $1150{ }^{\circ} \mathrm{C}, 2 \mathrm{D}$.

[Figure 2: SEM images of samples densified at (a) $900{ }^{\circ} \mathrm{C}$, $1 \mathrm{~A}$ and $a t(b) 1150^{\circ} \mathrm{C}, 2 \mathrm{D}$.]

III mostra os resultados de porosidade e tamanho de grão, obtidos por análise de imagens, nas pastilhas densificadas a $1150{ }^{\circ} \mathrm{C}$. Valores de porosidade variando entre 1,28 e
$14,34 \%$ e diâmetro médio de grão na faixa 1 a $2 \mu \mathrm{m}$ foram obtidos. Os valores de tamanhos de grão encontrados estão em concordância com os resultados obtidos por outros grupos ao estudar corpos densos de fosfato de cálcio [7, 12]. Como esperado, com o aumento da pressão de compactação a porosidade diminuiu. A grande variação na porosidade pode ser consequência da não uniformidade de compactação decorrente da prensagem uniaxial. Observou-se nas amostras sinterizadas a $1150^{\circ} \mathrm{C}$ que o aumento do tempo de sinterização de 2 para $4 \mathrm{~h}$ acarretou crescimento médio de grão de $22 \%$. No entanto, não houve correlação significativa entre os parâmetros empregados no preparo das pastilhas e os resultados de tamanho de grão e porosidade.

A Fig. 3 mostra os padrões de DRX das amostras

Tabela III - Quantificação de porosidade e tamanho de grão das pastilhas sinterizadas a $1150{ }^{\circ} \mathrm{C}$.

[Table III - Porosity and grain size quantification of tablets sintered at $1150^{\circ} \mathrm{C}$.]

\begin{tabular}{ccccc}
\hline & \multicolumn{3}{c}{ Porosidade } & \multicolumn{2}{c}{ Diâmetro médio de grão } \\
Fração & $\begin{array}{c}\text { D.P. } \\
\text { volumétrica } \\
(\%)\end{array}$ & $\begin{array}{c}\text { Diâmetro } \\
(\%)\end{array}$ & $\begin{array}{c}\text { D.P. } \\
(\mu \mathrm{m})\end{array}$ & $(\mu \mathrm{m})$ \\
\hline 1C & 10,76 & 6,43 & 1,24 & 0,13 \\
1D & 5,87 & 3,39 & 1,68 & 0,07 \\
2C & 3,64 & 2,31 & 1,30 & 0,28 \\
2D & 1,28 & 1,01 & 1,52 & 0,13 \\
3C & 14,34 & 2,77 & 1,33 & 0,10 \\
3D & 13,06 & 2,73 & 1,37 & 0,10 \\
4C & 9,15 & 5,77 & 1,07 & 0,13 \\
4D & 1,83 & 1,32 & 1,47 & 0,12 \\
\hline
\end{tabular}

sinterizadas a $1150{ }^{\circ} \mathrm{C}$ e também o padrão do pó de apatita cálcio-deficiente como recebido ( $\mathrm{CR}$, não calcinado) e do pó calcinado a $650{ }^{\circ} \mathrm{C}$ por $30 \mathrm{~min}$ (calc.). No pó como recebido foram identificadas as fases: hidroxiapatita $\left(\mathrm{Ca}_{5}\left(\mathrm{PO}_{4}\right)_{3} \mathrm{OH}\right.$, ficha JCPDS 73-0294) e monetita $\left(\mathrm{CaHPO}_{4}\right.$, arquivo JCPDS 71-1760). Após calcinação foi identificada hidroxiapatita com baixa cristalinidade e, com a sinterização, os principais picos presentes foram associados ao $\beta$-TCP, ficha arquivo JCPDS 09-0169. Também nas amostras sinterizadas a $900{ }^{\circ} \mathrm{C}$ (padrões não mostrados na figura), não foram encontradas outras fases que não $\beta$-TCP.

A Fig. 4 apresenta os espectros de FTIR do pó antes e após a calcinação (CR e calc., respectivamente) e das amostras sinterizadas a $1150{ }^{\circ} \mathrm{C}$. Os espectros do pó antes e após calcinação apresentam as bandas características do fosfato: $599 \mathrm{~cm}^{-1}$ e $560 \mathrm{~cm}^{-1}$, relativas ao modo de flexão de O-P-O; $1024 \mathrm{~cm}^{-1}$ e $1089 \mathrm{~cm}^{-1}$, correlacionadas ao estiramento assimétrico de O-P-O; e $961 \mathrm{~cm}^{-1}$, relativa ao estiramento simétrico de O-P-O. Observou-se redução dessas bandas nas amostras sinterizadas, fato esperado na densificação de $\beta$-TCP [22-24]. 


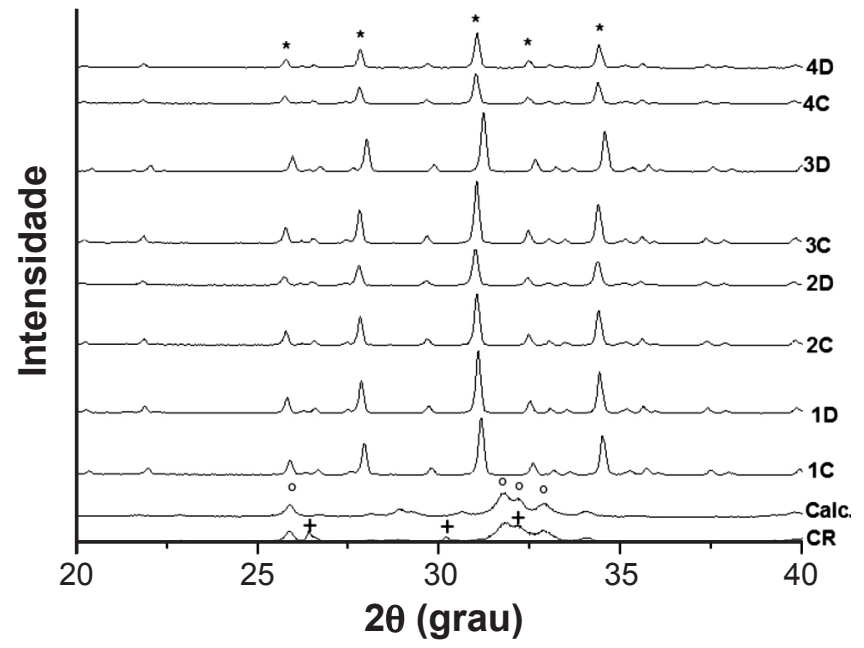

Figura 3: Padrões de difração de raios $\mathrm{X}$ das amostras sinterizadas a $1150{ }^{\circ} \mathrm{C}$. CR corresponde ao pó de apatita cálcio-deficiente como recebido (não calcinado); Calc. corresponde ao pó calcinado a $650{ }^{\circ} \mathrm{C}$ por $30 \mathrm{~min}$. As fases identificadas por: $\left(^{\circ}\right)$ corresponde à hidroxiapatita, $\left(^{+}\right)$é referente à monetita e a fase $(*)$ corresponde ao $\beta$-TCP.

[Figure 3: X-ray diffraction patterns of tablets sintered at $1150{ }^{\circ} \mathrm{C} . \mathrm{CR}$ refers to as-received (non-calcined) calcium deficient hydroxyapatite powder; Calc. is related to the powder calcined at $650^{\circ} \mathrm{C}$ for $30 \mathrm{~min}$. The phase identified as $\left(^{\circ}\right)$ corresponds to hydroxyapatite, $\left(^{+}\right)$refers to monetite and (*) corresponds to $\beta$-TCP.]

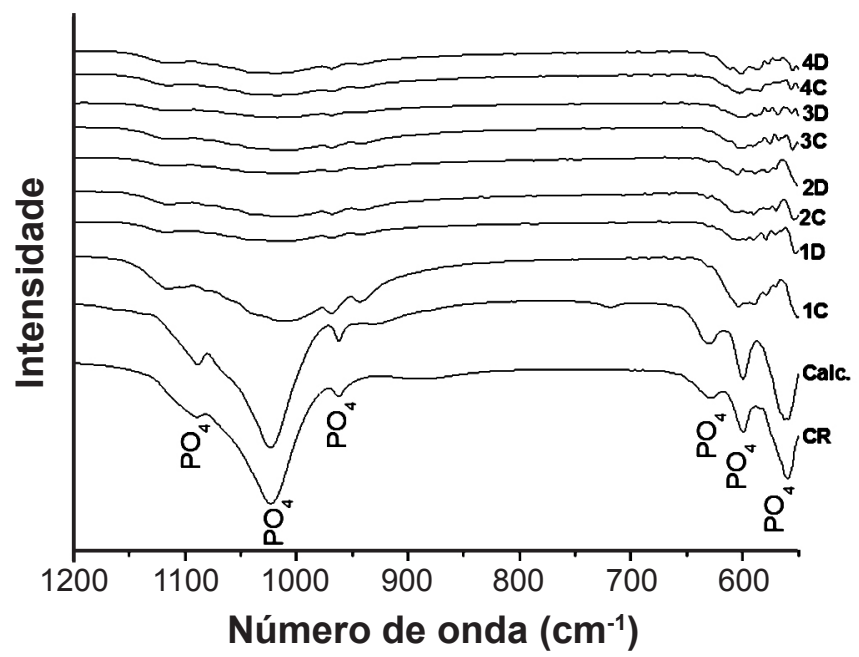

Figura 4: FTIR das amostras sinterizadas a $1150{ }^{\circ} \mathrm{C}$. (CR: pó como recebido (não calcinado); Calc.: pó calcinado).

[Figure 4: FTIR of the samples sintered at $1150^{\circ} \mathrm{C}$. (CR: asreceived (non-calcined) powder Calc.: calcined powder).]

Como as amostras efetivamente densas foram sinterizadas em temperatura superior à temperatura de transformação de fase $\beta \rightarrow \alpha$, poderia haver presença de microtrincas e de fase $\alpha$ retida. No entanto, não foram observadas trincas nas análises microestruturais e as pastilhas apresentavam somente fase $\beta$.

\section{CONCLUSÕES}

As amostras sinterizadas a $900{ }^{\circ} \mathrm{C}$ não apresentaram completa densificação. As pastilhas sinterizadas a $1150{ }^{\circ} \mathrm{C}$, compostas apenas de $\beta$-TCP, apresentaram maior densificação e menor porosidade. O tamanho médio de grão dessas amostras está na faixa 1-2 $\mu \mathrm{m}$. O aumento da pressão de compactação de 28 para $111 \mathrm{MPa}$ na produção das pastilhas foi efetivo para o aumento da microdureza das amostras. A retração linear máxima nas amostras sinterizadas a $1150{ }^{\circ} \mathrm{C}$ foi de aproximadamente $20 \%$. As variáveis de maior significância para densificação de pastilhas de $\beta$-TCP foram temperatura de sinterização, pressão de compactação e tempo de sinterização. Não foi identificada transformação de fase $\beta \rightarrow \alpha$ nas pastilhas sinterizadas a $1150{ }^{\circ} \mathrm{C}$, o que, provavelmente, contribuiu para que não fossem observadas microtrincas nas análises microestruturais.

\section{AGRADECIMENTOS}

Os autores agradecem o apoio financeiro da FAPERJ, da CAPES e do CNPq, e ao laboratório TERMIC pelo uso do software Image Pro-Plus $4.0^{\circledR}$.

\section{REFERÊNCIAS}

[1] M. Vallet-Regi, J. Chem. Soc., Dalton Trans. 2 (2001) 97.

[2] I. R. Gibson, I. Rehman, S. M. Best, W. Bonfield, J. Mater. Sci.: Mater. Med. 11 (2000) 533.

[3] D. A. Wahl, J. T. Czernuszka, Eur. Cells Mater. 11 (2006) 43.

[4] S. J. Kalita, R. Fleming, H. Bhatt, B. Schanen, R. Chakrabarti, Mater. Sci. Eng. C 28 (2008) 392.

[5] M. Lukic, Z. Stojanovic, S. D. Skapin, M. MacekKrzmanc, M. Mitric, S. Markovic, D. Uskokovic, J. Eur. Ceram. Soc. 31 (2011) 19.

[6] Y. Tanimoto, T. Hayakawa, T. Sakae, K. Nemoto, J. Biomed. Mater. Res. Part A 76A (2006) 571.

[7] F. H. Perera, F. J. Martínez-Vázquez, P. Miranda, A. L. Ortiz, A. Pajares, Ceram. Int. 36 (2010) 1929.

[8] Y. N. Mostafa, Mater. Chem. Phys. 94 (2005) 333.

[9] A. Slosarczyk, J. Bialoskorski, J. Mater. Sci.: Mater. Med. 9 (1998) 103.

[10] V. Jokanovic, B. Jokanovic, D. Markovic, V. Zivojinovic, S. Pasalic, D. Izvonar, M. Plavsic, Mater. Chem. Phys. 111 (2008) 180.

[11] A. I. Mitsionis, T. C. Vaimakis, C. C. Trapalis, Ceram. Int. 36 (2010) 623.

[12] O. Prokopiev, I. Sevostianov, Mater. Sci. Eng. A 431 (2006) 218.

[13] H. Y. Yang, S. F. Yang, X. P. Chi, J. R. G. Evans, I. Thompson, R. J. Cook, P. Robinson, J. Eur. Ceram. Soc. 28 (2008) 159.

[14] H. Ryu, H. Youn, K. S. Hong, B. Chang, C. Lee, S. Chung, Biomater. 23 (2002) 909.

[15] H. M. Silva, M. Mateescu, A. Ponche, C. Damia, E. 
Champion, G. Soares, K. Anselme, Colloids Surf. B: Biointerfaces 75 (2010) 349.

[16] I. C. Sinka, KONA 25 (2007) 4.

[17] F. R. Albuquerque, I. M. G. Santos, S. J. G. Lima, M.

R. Cássia-Santos, L. E. B. Soledade, A. G. Souza, A. E. Martinelli, Cerâmica 53, 327 (2007) 300.

[18] ASTM Standard E112-10, Standard Test Methods for Determining Average Grain Size (2010).

[19] S. V. Dorozhkin, Biomater. 31 (2010) 1465.

[20] M. K. Herliansyah, M. Hamdi, A. Ide-Ektessabi, M. W.
Wildan, J. A. Toque, Mater. Sci. Eng. C 29 (2009) 1674.

[21] B. Viswanath, R. Raghavan, N. P. Gurao, U. Ramamurty, N. Ravishankar, Acta Biomaterialia 4 (2008) 1448.

[22] P. G. Coelho, M. E. Coimbra, C. Ribeiro, E. Fancio, O. Higa, M. Suzuki, M. Marincola, Mater. Sci. Eng. C 29 (2009) 2085.

[23] D. K. Pattanayak, R. Dash, R. C. Prasad, B. T. Rao, T. R. Mohan, Mater. Sci. Eng. C 27 (2007) 684.

[24] S. Pramanik, A. K. Agarwal, K. N. Rai, A. Garg, Ceram. Int. 33 (2007) 419.

(Rec. 15/05/2011, Rev. 29/06/2011, Ac. 28/10/2011) 